\title{
KARAKTERISTIK KEKUATAN OTOT, KELENTURAN TUBUH, KOMPOSISI TUBUH DAN INDEKS MASSA TUBUH SISWA SMK NEGERI 5 DENPASAR TAHUN AJARAN 2014/2015
}

\author{
Dhivya Reddy Ramadas \\ ${ }^{1}$ Program Studi Pendidikan Dokter, Fakultas Kedokteran Universitas Udayana \\ (Dhivya3.dr@gmail.com)
}

\begin{abstract}
ABSTRAK
Latar Belakang

Seseorang memiliki tingkat kebugaran yang baik apabila melakukan latihan 3-5 kali seminggu, dan mengalokasikan 3 jam pelajaran dalam struktur kurikulum pendidikan jasmani sedangkan pelaksanaan pendidikan jasmani di SMK Negeri 5 Denpasarmengalokasi waktu latihan yakni 1 kali dalam seminggu dengan durasi 60 menit.
\end{abstract}

\section{Tujuan Penelitian}

Untuk mengetahui status fisik dalam aspek kekuatan otot, kelenturan badan, komposisi tubuh, dan indeks massa tubuh siswa-siswi SMK Negeri 5 Denpasar.

\section{Metode Penelitian}

Penelitian ini merupakan penelitian deskriptif kuantitatif untuk mengetahui status fisik dari kekuatan otot, kelenturan otot, komposisi lemak tubuh, dan indeks massa tubuh pada siswa SMK Negeri 5 Denpasar. Sampel penelitian ini sebanyak 43 orang siswa.

\section{Hasil Penelitian}

Rata-rata kekuatan genggam tangan kiri 28,48 \pm 14,243; kekuatan otot genggam tangan kanan 26,49 $\pm 17,069$; kekuatan otot punggung $89,83 \pm 40,921$; kekuatan otot kaki $74,49 \pm 37,861$. Kelenturan tubuh didapatkan ratarata $6,42 \pm 5,343$. Komposisi lemak tubuh didapatkan rata-rata $11,82 \pm 3,589$. Rata-rata indeks massa tubuh $20,97 \pm 1,992$.

\section{Kesimpulan}

Frekuensi latihan sampel sebagian besar hanya 1 kali perminggu. Durasi latihan sebagian besar 1 jam dalam satu kali latihan. Sebagian besar memiliki kekuatan otot poor dan very poor. Sebagian besar laki-laki memiliki kelenturan tubuh average dan good. Sebagian besar perempuan memiliki kelenturan tubuh average. Komposisi lemak tubuh rata-rata pada sampel $11,82 \pm 3,58$. Sebagian besar subyek memiliki indeks massa tubuh normal.

Kata Kunci: Kekuatan otot, kelenturan tubuh, komposisi tubuh, indeks massa tubuh.

\section{CHARACTERISTICS OF MUSCLE STRENGTH, BODY FLEXIBILITY, BODY COMPOSITION AND BODY MASS INDEX IN THE STUDENTS OF SMK NEGERI 5 DENPASAR YEAR 2014/2015}

\section{ABSTRACT \\ Background}

Someone has a good level of fitness when exercising 3-5 times a week, and allocate 3 hours of lessons in physical education curriculum structure while the implementation of physical education in SMK Negeri 5 Denpasar allocate training time which is 1 times a week with a duration of 60 minutes.

\section{Purposes}

To determine the physical status of the aspects of muscle strength, body flexibility, body composition, and body mass index of students of SMK Negeri 5 Denpasar.

\section{Methods}

This study is a quantitative descriptive research to determine the physical status of muscle strength, muscle tone, body fat composition, and body mass index in the students of SMK Negeri 5 Denpasar. The sample of this study were 43 students.

Result 
Average of the left hand grip strength $28.48 \pm 14.243$; right-hand grip strength $26.49 \pm 17.069$; the strength of the back muscles $89.83 \pm 40.921$; leg muscle strength $74.49 \pm 37.861$. Body flexibility obtained an average of $6.42 \pm 5.343$. Body fat composition obtained an average $11.82 \pm 3.589$. The average body mass index of $20.97 \pm$ 1.992.

\section{Conclusion}

Frequency of sample exercises mostly only 1 time per week. The duration of most of the 1-hour exercise in one workout. Most have poor and very poor muscle strength. Most men have average body flexibility and good. Most women have a average body flexibility. The composition of body fat on average at $11.82 \pm 3.58$. Most subjects had a normal body mass index.

Keywords: muscle strength, body flexibility, body composition, body mass index.

\section{LATAR BELAKANG}

Kebugaran jasmani adalah kondisi jasmani yang bersangkut paut dengan kemampuan dan kesanggupannya berfungsi dalam pekerjaan secara optimal dan efisien. Menurut U. Z. Mikdar, kebugaran jasmani adalah kemampuan tubuh seseorang untuk melakukan tugas dan pekerjaan sehari-hari tanpa menimbulkan kelelahan yang berarti, sehingga tubuh masih memiliki simpanan tenaga untuk mengatasi beban kerja tambahan. ${ }^{[1]}$ Kebugaran jasmani merupakan suatu keadaan yang dimiliki atau dicapai seseorang dalam kaitannya terhadap kemampuan untuk melakukan aktivitas fisik. Seseorang yang secara fisik bugar dapat melakukan aktivitas fisik sehari-harinya dengan giat, memiliki risiko rendah dalam masalah kesehatan dan dapat menikmati olahraga serta berbagai aktivitas lainnya.Pada hakekatnya kebugaran jasmani berhubungan dengan komponen-komponen tubuh manusia dan merupakan dasar kemampuan seseorang untuk melakukan kegiatan sehari-hari dengan baik.

Untuk memelihara pertumbuhan fisik dan menjaga kesegaran jasmani, tidak hanya dengan melakukan olahraga yang terprogram dan terencana dengan baik, tetapi juga harus ditunjang oleh makanan bergizi, lingkungan yang sehat dan tidak tercemar. Kebugaran jasmani sangat erat kaitannya dengan kegiatan manusia dalam melakukan pekerjaan dan bergerak.

Pendidikan jasmani adalah proses pendidikan via aktivitas jasmani, permainan dan atau olahraga. Jadi, yang digunakan sebagai medium atau perantara disini adalah serangkaian aktivitas jasmani, permainan atau cabang olahraga. ${ }^{[2]}$ Menurut Adeng Suherman, yang mengatakan bahwa pendidikan jasmani pada dasarnya merupakan pendidikan melalui aktivitas jasmani untuk mencapai perkembangan individu secara menyeluruh. ${ }^{[3]}$

Sudah menjadi semacam kesepakatan umum bahwa tujuan pembelajaran dalam domain psikomotor yang harus dikembangkan melalui program pendidikan jasmani harus pula mencakup peningkatan kebugaran jasmani siswa. Apakah kebugaran jasmani ini dapat dicapai melalui program pendidikan jasmani yang alokasi waktunya sangat minim. Apakah mungkin kebugaran jasmani siswa dapat ditingkatkan ketika anak harus pula mencapai tujuan pembelajaran yang lain.

SMK Negeri 5 Denpasar merupakan salah satu sekolah menengah kejuruan berakreditasi A di Kotamadya Denpasar. Sekolah ini berlokasi di Jalan Ratna No.17, Denpasar Provinsi Bali, Indonesia. ${ }^{[4]}$ Di SMK Negeri 5 Denpasar menunjukkan bahwa masih banyak siswa yang tidak mampu untuk mengikuti kegiatan pembelajaran pendidikan jasmani dengan maksimal karena mereka mudah mengalami kelelahan. Hal tersebut menjadi suatu masalah tersendiri bagi mata pelajaran pendidikan jasmani karena pendidikan jasmani dituntut untuk meningkatkan serta mempertahankan tingkat kebugaran jasmani siswa. Pelaksanaan pendidikan jasmani di sekolah ini mengalokasi waktu latihan yakni 1 kali dalam seminggu dengan durasi 60 menit. Pelaksanaan mengambil waktu pagi hari untuk kelas $\mathrm{X}$ dan sore hari untuk kelas XI dan XII. Dalam struktur kurikulum pelajaran pendidikan jasmani mengalokasikan 3 jam pelajaran yang merupakan jumlah minimal setiap kelas yang dapat ditambah sesuai kebutuhan peserta didik. ${ }^{[5]}$ Menurut Djoko Pekik Irianto, seseorang memiliki tingkat kebugaran yang baik apabila melakukan latihan 3-5 kali seminggu. ${ }^{[6]}$

Komponen kebugaran jasmani yang berhubungan dengan kesehatan meliputi kekuatan otot, daya tahan otot, kelenturan, daya tahan kardiorespirasi, dan komposisi tubuh. ${ }^{[7,8]} \mathrm{Hal}$ ini dipengaruhi oleh berbagai hal antara lain umur, jenis kelamin, genetik, ras, aktifitas fisik termasuk latihan, dan kadar hemoglobin. ${ }^{[9,10,11,12]}$

Beberapa penelitian tentang kesegaran jasmani berkaitan dengan komposisi tubuh telah dilakukan. Penelitian pada laki-laki dewasa di Jepang menunjukkan bahwa kesegaran jasmani laki-laki obesitas lebih rendah dibandingkan subyek normal atau borderline. ${ }^{[13]} \mathrm{Hal}$ ini hampir serupa dengan penelitian di Jakarta yang mengukur tingkat kesegaran jasmani secara umum yakni 
didapatkan bahwa makin tinggi persen lemak tubuh makin rendah tingkat kesegaran jasmaninya. ${ }^{[14]}$

Selain kebugaran jasmani yang baik, seorang siswa hendaknya juga harus memiliki indek masa tubuh yang ideal, karena dengan indeks massa tubuh yang ideal memungkinkan seseorang akan mencapai derajat kesehatan yang baik. Indeks massa tubuh dipakai sebagai salah satu indikator untuk mempresentasikan status gizi dan merupakan suatu indeks yang responsif dan sensitif terhadap perubahan keadaan gizi dan produktifitas kerja ${ }^{[15,16]}$

Beranjak masalah di atas, peneliti ingin mengetahui tingkat kebugaran jasmani siswa dalamaspek kekuatan otot, kelenturan tubuh, komposisi tubuh, dan indeks massa tubuh pada siswa SMK Negeri 5 Denpasar.

\section{METODE PENELITIAN}

Penelitian ini menggunakan rancangan deskriptif potong lintang untuk mengetahui status fisik dari kekuatan otot, kelenturan otot, komposisi lemak tubuh, dan indeks massa tubuh pada siswa sekolah menengah kejuruan di Denpasar.

Penelitian ini dilakukan pada 19-20 Maret 2015 bertempat di area lapangan sekolah SMK Negeri 5 Denpasar. Sampel penelitian ini adalah siswa-siswi SMK Negeri 5 Denpasar sebanyak 43 orang siswa, 22 siswa laki-laki dan 21 siswa perempuan. Metode pengumpulan data adalah dengan pengukuran langsung pada subyek yang bersedia sesuai variabel-variabel pada penelitian yang dipilih secara consecutive sampling. Kriteria inklusi sampel penelitian ini adalah siswa kelas $\mathrm{X}, \mathrm{XI}$, atau XII SMK Negeri 5 Denpasar yang bersedia menjadi sampel penelitian.

Variabel dalam penelitian ini adalah kekuatan otot, kelenturan tubuh, indeks masa tubuh, dan komposisi tubuh. Kekuatan otot yang dimaksud adalah mengukur kekuatan otot statis isometrik seperti kekuatan genggam tangan, kekuatan otot punggung, dan kekuatan otot kaki. Kelenturan tubuh yang dimaksud adalah luas gerak sendi (standing bending reach)yang diukur dengan alat standing trunk flexion meter. Indeks masa tubuh yang dimaksud adalah hasil penghitungan berat badan dalam satuan kilogram dibagi dengan kuadrat tinggi badan dalam satuan meter. Komposisi tubuh yang dimaksud adalah hasil pengukuran lemak tubuh subkutan di bagian belakang lengan, pinggang, dan paha.Dalam pelaksanaan penelitian, subyek diukur lemak pinggang, dan tidak dapat diukur lemak subskapula dan paha.

Instrumen penelitian yang digunakan adalahhandgrip dynamometer, back and leg dynamometer, standing trunk flexion meter, harpenden skinfold caliper, microtoise, dan timbangan badandengan tes dan pengukuran yang meliputi:

Tes kekuatan otot genggam. Tujuan tes ini adalah mengukur kemampuan genggaman tangan kanan dan kiri. Tes ini menggunakan alat handgrip dynamometer. Prosedur ini diulang 3 kali kemudian diambil nilai paling tinggi.

Tes kekuatan otot punggung dan kaki. Tujuan tes ini adalah mengukur kekuatan otot punggung dan otot kaki. Tes ini menggunakan alat back and leg dynamometer.Hasil pengukuran kemudian dicatat. Prosedur ini diulang 3 kali kemudian diambil nilai pengukuran paling tinggi.

Tes kelenturan tubuh. Tujuan dari tes ini adalah untuk menilai kelenturan tubuh. Tes ini menggunakan alat standing trunk flexion meter.

Pengukuran lemak subkutan. Tujuan dari pengukuran ini adalah untuk mengukur ketebalan lemak tubuh pada lokasi subskapular, brachii posterior, dan pinggang.

Pengukuran berat badan. Pembacaan berat badan dalam kilogram.

Pengukuran tinggi badan.Pembacaan tinggi badan dalam sentimeter.

Pengukuran indeks massa tubuh. Tujuan dari pengukuran ini adalah untuk mengetahui proporsi tubuh. Dengan data berat badan dan tinggi badan, kemudian dilakukan kalkulasi untuk mencari indeks massa tubuh sesuai metode WHO (World Health Organization) dengan formula

$$
\operatorname{IMT}=\frac{\text { berat badan }(\mathrm{kg})}{[\text { Tinggi badan }(\mathrm{m})]^{2}}
$$

Setelah semua data terkumpul, dilakukan penghitungan-penghitungan statistik deskriptif kemudian dianalisis denganperangkat lunak komputer SPSS ver20.

\section{HASIL}

Keseluruhan subyek (Tabel $1 \& 2$ ) berjumlah 43 orang terdiri dari 22 laki-laki $(51,2 \%)$ dan 21 perempuan $(48,8 \%)$. Karakteristik usia rata-rata $16,93 \pm 0,799$ dengan usia minimal 15 tahun sebanyak $1(2,3)$ sampel dan maksimal 19 tahun sebanyak 1 (2,3\%) sampel. Pada sampel ditemukan 11 (25,6\%) sampel berusia 16 tahun dan 22 (51,2\%) sampel berusia 17 tahun.

Berdasarkan frekuensi latihan yang paling sering yaitu 6 kali per minggu sebanyak 1 (2,3\%) sampel dan minimal 1 kali per minggu sebanyak 19 (44,2\%) sampel dengan rata-rata frekuensi latihan 1,98 $\pm 1,123$ kali per minggu. Berdasarkan durasi latihan rata-rata 1,30 \pm 0,639 jam setiap latihan. Didapatkan durasi minimal 1 jam pada $33(76,7 \%)$ sampel dan paling lama 4 
jam pada $1(2,3 \%)$ sampel. Tinggi badan rata-rata subyek $162,57 \pm 6,924 \mathrm{~cm}$ dengan tinggi paling rendah $149 \mathrm{~cm}$ dan paling tinggi $175 \mathrm{~cm}$. berat badan rata-rata subyek
$55,70 \pm 7,827 \mathrm{~kg}$ dengan berat badan minimum $36 \mathrm{~kg}$ dan maksimum $70 \mathrm{~kg}$.

Tabel 1, Data Karakteristik Sampel

\begin{tabular}{|c|c|c|}
\hline Karakteristik & $\mathbf{N}$ & $\%$ \\
\hline \multicolumn{3}{|l|}{ Jenis kelamin } \\
\hline Laki-laki & 22 & 51,2 \\
\hline Perempuan & 21 & 48,8 \\
\hline \multicolumn{3}{|l|}{ Umur (tahun) } \\
\hline 15 & 1 & 2,3 \\
\hline 16 & 11 & 25,6 \\
\hline 17 & 22 & 51,2 \\
\hline 18 & 8 & 18,6 \\
\hline 19 & 1 & 2,3 \\
\hline \multicolumn{3}{|c|}{ Frekuensi latihan ( kali per minggu ) } \\
\hline 1 & 19 & 44,2 \\
\hline 2 & 11 & 25,6 \\
\hline 3 & 10 & 23,3 \\
\hline 4 & 2 & 4,7 \\
\hline$\geq 5$ & 1 & 2,3 \\
\hline \multicolumn{3}{|c|}{ Durasi latihan ( jam ) } \\
\hline 1 & 33 & 76,7 \\
\hline 2 & 8 & 18,6 \\
\hline$\geq 3$ & 2 & 4,6 \\
\hline
\end{tabular}

Keterangan $: \mathrm{N}=$ jumlah sampel

Dari tabel 3, memperlihatkan status fisik subyek yakni berdasarkan kekuatan otot (kekuatan genggam, kekuatan otot punggung, dan kekuatan otot kaki) didapatkan rata-rata kekuatan genggam tangan kiri $28,48 \pm 14,243$; pada laki-laki 38,84 $\pm 11,785$ dan pada perempuan $17,62 \pm 6,182$. Kekuatan otot genggam tangan kanan 26,49 \pm 17,069; pada laki-laki 34,45 \pm 11,185 dan perempuan $18,14 \pm 18,373$. Kekuatan otot punggung $89,83 \pm 40,921$; pada laki-laki $125,36 \pm 19,478$ dan perempuan $52,62 \pm 16,594$. Kekuatan otot kaki
$74,49 \pm 37,861$; pada laki-laki 105,23 \pm 24,134 dan perempuan $42,30 \pm 16,485$. Berdasarkan kelenturan tubuh didapatkan rata-rata $6,42 \pm 5,343$; pada laki-laki $7,01 \pm 3,814$ dan perempuan 6,42 $\pm 5,343$. Komposisi lemak tubuh didapatkan rata-rata 11,82 $\pm 3,589$; pada sampel laki-laki $10,30 \pm 3,294$ dan pada sampel perempuan $13,42 \pm 3,227$. Rata-rata indeks massa tubuh (IMT) 20,97 \pm 1,992; pada sampel laki-laki 21,38 $\pm 1,178$ dan pada sampel perempuan $20,54 \pm 2,549$.

Tabel 2, Gambaran Umur, Frekuensi Latihan, Durasi Latihan, Tinggi Badan, dan Berat Badan

\begin{tabular}{lrrr}
\hline & Minimum & Maksimum & $\begin{array}{c}\text { Mean } \\
\pm \text { Standar Deviasi }\end{array}$ \\
\hline Umur & & 19 & $16,93 \pm 0,799$ \\
Frekuensi latihan (kali per minggu) & 15 & 6 & $1,98 \pm 1,123$ \\
Durasi latihan (jam) & 1 & 4 & $1,30 \pm 0,639$ \\
Tinggi badan (sentimeter) & 1 & 175 & $162,57 \pm 6,924$ \\
Berat badan (kilogram) & 149 & 70 & $55,70 \pm 7,827$ \\
\hline
\end{tabular}

Dari tabel 4, memperlihatkan interpretasi kekuatan otot genggam tangan kiri dan kanan pada lakilaki serta pada perempuan. Pada laki-laki, interpretasi kekuatan genggam tangan kiri, 2 (9,09\%) termasuk very good, 3 (13,64\%) termasuk above average, 2 (9,09\%) termasuk below average, 4 (18,18\%) termasuk poor, 11 $(50,0 \%)$ termasuk very poor, dan tidak ada yang termasuk excellent dan average. Interpretasi kekuatan genggam tangan kanan, 1 (4,55\%) termasuk very good, 2 $(9,09 \%)$ termasuk average, $3(13,64 \%)$ termasuk below average, 1 (4,55\%) termasuk poor, $15(68,17)$ termasuk very poor, dan tidak ada (0\%) yang termasuk kategori excellent dan above average.Pada perempuan, interpretasi kekuatan genggam tangan kiri, 1 (4,76\%) 
termasuk above average, 1 (4,76\%) termasuk average, 3 $(14,29 \%)$ termasuk below average, $2(9,52)$ termasuk poor, $14(66,67)$ termasuk very poor, dan tidak ada yang termasuk kategori excellent dan very good. Interpretasi kekuatan genggam tangan kanan 1 (4,76\%) termasuk excellent, 3 (14,29\%) termasuk below average, 1 (4,76\%) termasuk poor, 16 (76,19\%) termasuk very poor, dan tidak ada (0\%) yang tergolong kategori very good, above average, dan average.

Tabel 3, Status Fisik

\begin{tabular}{|c|c|c|c|}
\hline & \multicolumn{2}{|c|}{ Jenis kelamin } & \multirow{3}{*}{ Rata-rata total } \\
\hline & Laki-laki & Perempuan & \\
\hline & Rata-rata \pm SD & Rata-rata \pm SD & \\
\hline \multicolumn{4}{|l|}{$\begin{array}{l}\text { Kekuatan otot } \\
\text { genggam tangan }\end{array}$} \\
\hline Tangan kiri & $38,84 \pm 11,785$ & $17,62 \pm 6,182$ & $28,48 \pm 14,243$ \\
\hline Tangan kanan & $34,45 \pm 11,185$ & $18,14 \pm 18,373$ & $26,49 \pm 17,069$ \\
\hline Otot punggung & $125,36 \pm 19,478$ & $52,62 \pm 16,594$ & $89,83 \pm 40,921$ \\
\hline Kekuatan otot kaki & $105,23 \pm 24,134$ & $42,30 \pm 16,485$ & $74,49 \pm 37,861$ \\
\hline Kelenturan tubuh & $7,01 \pm 3,814$ & $6,42 \pm 5,343$ & $6,42 \pm 5,343$ \\
\hline Komposisi tubuh & $10,30 \pm 3,294$ & $13,42 \pm 3,227$ & $11,82 \pm 3,589$ \\
\hline Indeks Massa Tubuh & $21,38 \pm 1,178$ & $20,54 \pm 2,549$ & $20,97 \pm 1,992$ \\
\hline
\end{tabular}

Dari tabel 5, memperlihatkan interpretasi kelenturan tubuh pada laki-laki dan perempuan. Pada laki-laki, 1 (4,54\%) termasuk kategori excellent, 10 $(45,46 \%)$ termasuk kategori good, 11 (50,0\%) termasuk average, tidak ada (0\%) yang termasuk kategorisuper, fair, poor, dan very poor.
Dari tabel 6, memperlihatkan indeks massa tubuhberdasarkan kriteria WHO (World Health Organization) dengan 2 (4,7\%) termasuk kurus sekali, 3 $(7,0 \%)$ termasuk kurus, $36(83,7 \%)$ termasuk normal, 2 $(4,7 \%)$ termasuk gemuk, dan tidak ada (0\%) yang termasuk kategori gemuk sekali.

Tabel 4, Kekuatan Otot

\begin{tabular}{|c|c|c|c|c|c|c|c|c|}
\hline \multirow{4}{*}{ Interpretasi } & \multicolumn{8}{|c|}{ Jenis kelamin } \\
\hline & \multicolumn{4}{|c|}{ Laki-laki } & \multicolumn{4}{|c|}{ Perempuan } \\
\hline & \multicolumn{2}{|c|}{ Grip tangan kiri } & \multicolumn{2}{|c|}{ Grip tangan kanan } & \multicolumn{2}{|c|}{ Grip tangan kiri } & \multicolumn{2}{|c|}{ Grip tangan kanan } \\
\hline & $\mathrm{N}$ & $\%$ & $\mathrm{~N}$ & $\%$ & $\mathrm{~N}$ & $\%$ & $\mathrm{~N}$ & $\%$ \\
\hline Excellent & - & - & - & - & - & - & 1 & 4,76 \\
\hline Very good & 2 & 9,09 & 1 & 4,55 & - & - & - & - \\
\hline Above average & 3 & 13,64 & - & - & 1 & 4,76 & - & - \\
\hline Average & - & - & 2 & 9,09 & 1 & 4,76 & - & - \\
\hline Below average & 2 & 9,09 & 3 & 13,64 & 3 & 14,29 & 3 & 14,29 \\
\hline Poor & 4 & 18,18 & 1 & 4,55 & 2 & 9,52 & 1 & 4,76 \\
\hline Very poor & 11 & 50,00 & 15 & 68,17 & 14 & 66,67 & 16 & 76,19 \\
\hline Total & 22 & 100,00 & 22 & 100,00 & 21 & 100,00 & 21 & 100,00 \\
\hline
\end{tabular}

Keterangan: pada laki-laki: excellent (>64), very good (56-64), above average (52-56), average (48-52), below average (4446), poor (40-44), very poor (<40). Pada perempuan: excellent (>38), very good (34-38), above average (30-34), average (26-30), below average (22-26), poor (20-22), very poor $(<20) .{ }^{[17]}$ Satuan pengukuran dalam $\mathrm{kg}$.

\section{PEMBAHASAN}

Frekuensi latihan rata-rata pada siswa $1,98 \pm$ 1,123 kali per minggu. Berdasarkan durasi latihan ratarata $1,30 \pm 0,639$ jam setiap latihan. Dan didapatkan durasi latihan 1 jam pada 33 siswa (76,7\%). Menurut Syarifudin dan Sudrajat W, aspek ini dirasakan masih kurang karena dalam struktur kurikulum pelajaran pendidikan jasmani, olahraga, dan kesehatan mengalokasikan 3 jam pelajaran yang merupakan jumlah minimal setiap kelas yang dapat ditambah sesuai kebutuhan peserta didik. ${ }^{[5]}$ Menurut Djoko Pekik Irianto, 
Tabel 5, Kelenturan Tubuh

\begin{tabular}{|c|c|c|c|c|}
\hline \multirow{3}{*}{ Interpretasi } & \multicolumn{3}{|c|}{ Jenis kelamin } & \\
\hline & \multicolumn{2}{|c|}{ Laki-laki } & \multicolumn{2}{|c|}{ Perempuan } \\
\hline & $\mathrm{N}$ & $\%$ & $\mathrm{~N}$ & $\%$ \\
\hline Super & - & - & - & - \\
\hline Excellent & 1 & 4,54 & - & - \\
\hline Good & 10 & 45,46 & 5 & 23,81 \\
\hline Average & 11 & 50,00 & 11 & 52,38 \\
\hline Fair & - & - & 5 & 23,81 \\
\hline Poor & - & - & - & - \\
\hline Very poor & - & - & - & - \\
\hline Total & 22 & 100,00 & 21 & 100,00 \\
\hline
\end{tabular}

Tabel 6, Indeks Massa Tubuh (IMT)

\begin{tabular}{|c|c|c|c|c|c|c|c|c|c|c|}
\hline \multirow[b]{3}{*}{ IMT } & \multicolumn{10}{|c|}{ Berdasarkan kriteria WHO } \\
\hline & \multicolumn{2}{|c|}{ Kurus sekali } & \multicolumn{2}{|c|}{ Kurus } & \multicolumn{2}{|c|}{ Normal } & \multicolumn{2}{|c|}{ Gemuk } & \multicolumn{2}{|c|}{ Gemuk sekal } \\
\hline & $\mathrm{N}$ & $\%$ & $\mathrm{~N}$ & $\%$ & $\mathrm{~N}$ & $\%$ & $\mathrm{~N}$ & $\%$ & $\mathrm{~N}$ & $\%$ \\
\hline & 2 & 4,7 & 3 & 7,0 & 36 & 83,7 & 2 & 4,7 & 0 & 0 \\
\hline
\end{tabular}

Keterangan: kurus sekali <17, kurus $17-18,4$, normal 18,5-25,0, gemuk 25,1-27, gemuk sekali $>27$. Satuan pengukuran dalam $\mathrm{kg} / \mathrm{m}^{2}{ }^{2}[16,18]$

Komposisi lemak tubuh rata-rata pada sampel laki-laki10,30 $\pm 3,294$ milimeter dan pada perempuan $13,42 \pm 3,227$ milimeter. Dengan konversi, rata-rata lemak tubuh pada laki-laki $<6 \%$ dan pada perempuan $<$ $9 \%$. MenurutWallace CD,yang menyatakan bahwa angka persen lemak tubuh ideal berkisar antara $9-15 \%$ pada laki-laki dan $14-21 \%$ pada perempuan. Seseorang idealnya mempertahankan angka ini pada kisaran nilai ideal atau kurang dari batas atas ideal. Seseorang dengan angka di bawah batas bawah dikategorikan kurus. Dengan demikian, dari rata-rata pengukuran pada sampel laki-laki dan perempuan, tergolong kurus. ${ }^{[19]}$

\section{KESIMPULAN}

Berdasarkan hasil penelitian dan pembahasan maka disimpulkan bahwa frekuensi latihan sampel sebagian besar hanya 1 kali perminggu. Hanya sebagian kecil yang latihan 2-3 kali per minggu. Durasi latihan sampel sebagian besar 1 jam dalam satu kali latihan. Hanya sebagian kecil yang latihan dengan durasi 2 jam atau lebih.Sebagian besar siswa SMK Negeri 5 Denpasar memiliki kekuatan ototpoor dan very poor. Hanya sebagian kecil yang memiliki kekuatan otot below average.Sebagian besar siswa SMK Negeri 5 Denpasar pada laki-laki memiliki kelenturan tubuh average dan good, hanya sebagian kecil yang memiliki kelenturan tubuh excellent. Pada perempuan, sebagian besar memiliki kelenturan tubuh average, hanya sebagian kecil yang memiliki kelenturan tubuh good dan fair. Komposisi lemak tubuh rata-rata pada sampel 11,82 \pm 3,58, pada laki-laki10,30 $\pm 3,294$ milimeter dan pada perempuan 13,42 $\pm 3,227$ milimeter. Sebagian besar siswa SMK Negeri 5 Denpasar memiliki indeks massa tubuh normal. Hanya sebagian kecil yang memiliki indeks massa tubuh kurus dan gemuk.

Adapun keterbatasan pada penelitian ini yakni pengukuran komposisi tubuh yang sebaiknya ditambahkan variabel lemak subkutan subskapula dan paha. Serta pengukuran lingkar pinggang untuk memprediksi lemak visceral tubuh. Keterbatasan lain yakni peneliti tidak dapat mengontrol aktivitas dan kondisi fisik siswa sebelum pengambilan data, sehingga data yang diperoleh merupakan hasil pengambilan data seketika tanpa memperhatikan kondisi fisik siswa apakah mengalami kelelahan atau tidak sebelum pengambilan data.

\section{SARAN}


Berdasarkan kesimpulan dan keterbatasan penelitian di atas, ada beberapa saran yang dapat disampaikan yaitu:

1. Bagi siswa agar selalu menjaga kesegaran jasmaninya dengan cara membiasakan bergerak ringan seperti jalanjalan, jogging, dan lain sebagainya.

2. Bagi guru dan sekolah agar dapat mengalokasikan waktu latihan yang efektif dan memantau perkembangan kebugaran jasmani siswa-siswinya secara periodik, sehingga selalu terpantau dengan baik.

3. Bagi peneliti, hasil penelitian ini dapat dijadikan sebagai bahan masukan untuk mengembangkan dan menyempurnakan penelitian tentang tingkat kebugaran jasmani. Serta, dapat melakukan penelitian dengan menghubungkannya dengan variabel lain, baik itu mengganti ataupun dengan menambah variabel-variabel yang lain yang tidak terdapat dalam penelitian ini.

\section{DAFTAR PUSTAKA}

1. Mikdar, U Z. Hidup Sehat: Nilai Inti Berolahraga. Jakarta: Departemen Pendidikan Nasional, Direktorat Jendral Pendidikan Tinggi, Direktorat Ketenagaan; 2006.

2. Lutan, Rusli. Asas-Asas Pendidikan Jasmani. Jakarta: Departemen Pendidikan Nasional, Direktorat Jendral Pendidikan Dasar dan Menengah Berkerjasama dengan Direktorat Jendral Olahraga; 2001.

3. Suherman, Adeng. MA. Asesmen Belajar Dalam Pendidikan Jasmani. Jakarta: Direktorat Jendral Olahraga; 2001.

4. Kementerian Pendidikan dan Kebudayaan Direktorat Jenderal Pendidikan Menengah. 2013. Data Pokok PSMK [diakses 23 Maret 2015];1 [1]: [5 screen].Diunduh dari URL:http://datapokok.ditpsmk.net/detil.php?id=22 71020002 .

5. Syarifudin, Sudrajat W. Buku Guru Pendidikan Jasmani, Olahraga, dan Kesehatan. Jakarta: Kementerian Pendidikan dan Kebudayaan; 2014.

6. Irianto, Djoko Pekik. Panduan Latihan Kebugaran yang Efektif dan Aman. Yogyakarta: Andi offset; 1999.

7. Nieman D. The exercise test as a component of the total fitness evaluation. Primary Care Clinics in Office Practice 2001; 28 :1-13.

8. Amisola R, Jacobson M. Physical activity, exercise and sedentary activity: relationship to the causes and treatment of obesity. Adolescent Medicine. 2003; 14: 23-35.

9. Johnson B, Nelson J. Practical measurements for evaluation in physical education. 4th ed. New York: Macmillan Publishing Company ; 1986.
10. Bettiol H, Rona R, Chinn S. Variation in physical fitness between ethnic group in nine year olds.International Journal of Epidemiology. 1999; 28: 281-6.

11. Rowland A, Eston R, Ingledew D. Relationship between activity level, aerobic fitness, and body fat in 8-to 10-yr old children. J Appl Physiol. 1999; 86(4): 1428-35.

12. Gutin B, Barbeau $P$, Owens $S$, Lemmon $C$, Bauman $M$, Allison J, dkk. Effects of exercise intensity on cardiovascular fitness, total body composition, and viceral adiposity of obese children. Am J Clin Nutr. 2002; 75: 818-26.

13. Miyatake N, Nishikawa H, Fujii M. Clinical evaluation of physical fitness in male obese Japanese. Chin Med J. 2001; 114(7): 707-10.

14. Sahari T. Hubungan persen lemak tubuh dengan kesegaran jasmani menurut tes ACSPFT pada anak usia 6-12 tahun di 10 sekolah dasar di DKI Jakarta [tesis]. Jakarta: Universitas Indonesia; 1997.

15. Atmarita \& Fasli Jalal. Perhitungan, Penggunaan dan Interpretasi Berbagai Indek Anthropometi dalam Penilaian Status Gizi dengan Buku Rujukan WHO NCHS. Dalam Gizi Indonesia. Journal of The Indonesian Nutrition Association. 1991; 26: 1-2.

16. Husaini. Energi dan Berat Badan Usia Lanjut. Dalam Gizi Indonesia. Journal of The Indonesian Nutrition Association.1996; 26: 1-2.

17. Anggrain RA, Eki FT, Fauziyah FM, dkk. Kekuatan Otot. Laporan Praktikum. Surabaya: Universitas Airlangga. 2012.

18. Johan K.W., Henhy, Thomas. Sistem Pengukur Berat dan Tinggi Badan Menggunakan Mikrokontroler AT89S51. TESLA. 2008; 10(2): 7984.

19. Wallace CD. How to Measure \% Bodyfat. Michigan: Creative Health Product. 2009. 